\title{
Breast-milk levels of long-chain PUFA in Kazakhstan and Sweden
}

\author{
M. Xiang ${ }^{1}$, L. S. Harbige ${ }^{1,2}$ and R. Zetterström ${ }^{3}$ \\ ${ }^{1}$ Centre for Biosciences Research, School of Science, University of Greenwich, Kent ME4 4TB, UK, ${ }^{2}$ Medway School of \\ Pharmacy, University of Kent and University of Greenwich, Kent ME4 4TB, UK and ${ }^{3}$ Department of Paediatrics, \\ Karolinska Hospital, Karolinska Institute, Stockholm, Sweden
}

The deterioration of human health with increasing infant mortality rate, declining life expectancy at birth and increasing prevalence of serious infectious diseases in Russia and other former Soviet Republics is thought to be the result of a combination of several factors such as inadequate nutrition, poor sanitation, collapse of the healthcare system and pollution from Soviet agriculture and industries ${ }^{(1,2)}$. Environmental pollutants, which may occur in breast milk and in various food products and drinking water, and which are also transferred to the foetus, constitute a severe threat to the health of infants and children. In Kazakhstan, which is the second largest area of the former Soviet Republics with only eighteen million inhabitants, the situation is particularly alarming. Long-chain (LC) PUFA are essential dietary nutrients required for the optimal growth and development of infants, particularly of the brain and retina. It is important for exclusivelybreast-fed infants to receive milk of a correct balance between $n-6$ and $n-3$ fatty acids ${ }^{(3-5)}$. In the present study the composition of LC PUFA in the colostrum of Kazakh and Swedish mothers and the growth rate of their foetuses were compared. Ten and nineteen mother - term infant pairs from a countryside located about $600 \mathrm{~km}$ from Almaty, Kazakstan and Stockholm, Sweden, who were $1-5 \mathrm{~d}$ old and exclusively breast-fed, were studied. The colostrum of the Kazakh mothers had significantly higher linoleic acid (LA; 18: $2 n-6)$ and lower $\alpha$-linolenic acid (LNA; 18: 3n-3), arachidonic acid (AA; 20: 4n-6), EPA (20: 5n-3) and DHA (22: 6n-3) levels than those of the Swedish mothers. The recommended ranges for LA:LNA and AA:DHA in human milk are 5-10 and $0.5-1$ compared with 32.4 and 3.22 in the Kazakh breast milk, and 8.98 and 1.35 in the Swedish breast milk respectively (Table).

\begin{tabular}{|c|c|c|c|c|c|}
\hline \multirow[b]{2}{*}{ Ratio } & \multicolumn{2}{|c|}{ Kazakh $(n$ 10) } & \multicolumn{2}{|c|}{ Swedish $(n$ 19) } & \multirow[b]{2}{*}{$P$ value } \\
\hline & Mean & SE & Mean & SE & \\
\hline LA:LNA & 32.4 & 2.01 & 8.98 & 0.47 & $<0.001$ \\
\hline AA:DHA & 3.22 & 0.24 & 1.35 & 0.08 & $<0.001$ \\
\hline$\Sigma n-6 / \Sigma n-3$ PUFA & 24.6 & 1.16 & 6.13 & 0.26 & $<0.001$ \\
\hline$\Sigma n-6 / \Sigma n-3$ LC PUFA & 9.78 & 0.60 & 3.12 & 0.14 & $<0.001$ \\
\hline
\end{tabular}

The milk of the Kazakh mothers is less balanced in relation to the levels of $n-6$ and $n-3$ PUFA than that of the Swedish mothers. Whether environmental pollutants and/or PUFA might affect the developing immune and nervous systems in this Kazakh population could be followed up by a study of immune and neuro-functions of Kazakh and Swedish infants.

1. Zetterstrom R (1999) Acta Paediatr 429, 49-54.

2. Jensen S, Mazhitova Z \& Zetterstrom R (1997) Sci Total Environ 206, 187-193.

3. Xiang M, Harbige LS \& Zetterstrom R (2007) Acta Paediatr 96, 387-390.

4. Xiang M, Rahman MA, Ai H, Li X \& Harbige LS (2006) Ann Nutr Metab 50, 492-498.

5. Xiang M, Harbige LS \& Zetterström R (2005) Acta Paediatr 94, 1543-1549. 